\title{
Evaluation of lower functional gut disorders
}

\author{
Christopher N Andrews MD MSc FRCPC, Martin Storr MD
}

$T^{\text {hers. }}$ here is an element of the art of medicine in the diagnosis of functional lower gut disorders. Functional disorders are believed to be problems of normal gut function; by definition, they imply or require a lack of organic disease. With advanced understanding and reliable definitions of irritable bowel syndrome (IBS) in particular, the concept that these disorders are purely a diagnosis of exclusion is outdated. Their cardinal symptoms, however, such as abdominal pain, diarrhea or constipation, have huge lists of potential organic causes. The key is to know how much investigation is needed before making the diagnosis. Many factors will influence this process, from both the patient and practitioner viewpoints.

\section{IBS}

Functional gut disorders are exceedingly common in gastroenterology practices, with IBS being the most freqently seen (1). Abdominal discomfort is the cardinal feature of IBS and is

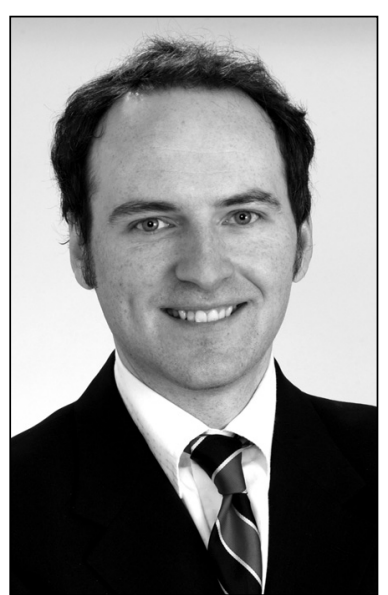

Dr Christopher $N$ Andrews

unintentional weight loss, hematochezia, or a family history of organic gastrointestinal diseases such as inflammatory bowel disease, celiac sprue or malignancy.

The American Gastroenterology Association position paper on IBS (3) suggests a complete blood count, with consideration of sedimentation rate (more so in younger patients), serum chemistry, albumin, and stool for ova and parasites based on symptom pattern, geographical area and relevant clinical features. Recent British Society of Gastroenterology guidelines (4) suggest a complete blood count and, possibly, celiac serology testing for patients with typical IBS symptoms without alarm features. Another review suggests that current evidence does not support the routine use of blood tests, stool studies, breath tests, abdominal imaging or lower endoscopy to exclude organic gastrointestinal disease in patients with typical IBS symptoms without alarm features, with the possible exception of celiac serology testing (5).

associated with altered bowel habits. The latest
version of the Rome criteria (Rome III) for IBS has lowered the bar even further for making the diagnosis (2). Whereas patients had to be symptomatic $25 \%$ of the time to meet diagnostic criteria for IBS by Rome II definitions, they now only need to experience symptoms $10 \%$ of the time, or three of 30 days. While recognizing that IBS is very common, the lower threshold makes it truly ubiquitous.

The patients with IBS referred to a gastroenterologist, however, generally tend to be more symptomatic or more resistant to therapy than can be managed in primary care. More commonly, patients with abdominal pain or altered bowel habits are referred, and it is up to the gastroenterologist to make the initial diagnosis. In both scenarios, the index of suspicion for organic disease may be significant, and these patients generally need evaluations. The most important guiding principle is obviously the patient's history, with alarm features and symptom severity necessitating more testing. However, a minimum standard of care is not well defined for the workup of IBS, and thus, the extent of evaluation is determined by the gastroenterologist. The objective of the present article is to discuss issues relevant to diagnostic tests in this area.

\section{ALTERNATING OR MIXED BOWEL PATTERN IBS} Mixed bowel pattern IBS (M-IBS), with alternating bowel habit between diarrhea and constipation, is the most common presentation of IBS and generally does not require an exhaustive workup. Typical symptoms meeting Rome criteria for IBS, coupled with an absence of alarm features, is usually sufficient to make the diagnosis. Alarm features include symptom onset after the age of 50 years, severe diarrhea, nocturnal symptoms,

University of Calgary, Calgary, Alberta

Correspondence: Dr Christopher N Andrews, University of Calgary Faculty of Medicine, Room 6D24, Teaching, Research and Wellness Building,

3280 Hospital Drive Northwest, Calgary, Alberta T2N 4N1. Telephone 403-592-5020, fax 403-592-5090, e-mail candrews@ucalgary.ca

Received for publication March 4, 2008 
diarrhea referred for colonoscopy, and in almost 20\% of those older than 70 years. Biopsy is required for the diagnosis of $\mathrm{MC}$, and it appears that any colonic location should be adequate based on a large series of MC patients (9). However, some studies have suggested that a small percentage of $\mathrm{MC}$ patients may have isolated right-sided disease (10); therefore, sampling from this area is suggested. If the patient previously had a colonoscopy without biopsy but assessment for MC is required, a flexible sigmoidoscopy with biopsy from the most proximal colon possible is reasonable.

Stool testing for culture, ova and parasites, and Clostridium difficile is important in patients who are elderly, institutionalized or immunosuppressed, patients with recent antibiotic use or patients who report febrile episodes. Patients living in areas where amoebic or parasitic infections, such as Giardia species, are common should also be tested. Other tests for causes of diarrhea are available but are not routinely required unless symptoms are particularly suggestive.

\section{CONSTIPATION-PREDOMINANT IBS}

The role for endoscopy in the evaluation of constipation alone is controversial. A position paper by the American Gastroenterology Association (11) suggested that a structural evaluation of the colon is appropriate for patients with constipation, but constipation was not included in the recommended indications for colonoscopy by a multisociety task force (12). Canadian guidelines on colon cancer screening suggest a diagnostic workup for patients who are symptomatic, but it does not define specifically what those symptoms are (13). It is clear that not every person presenting with constipationpredominant IBS (C-IBS) requires endoscopy, and an initial trial of fibre supplementation or laxatives is suggested.

However, in patients who fail to respond to these measures or in patients with alarm features, there is agreement that endoscopic evaluation should be performed. In our opinion, ageappropriate colorectal cancer screening should be performed with colonoscopy as per Canadian guidelines (13) in patients presenting with C-IBS; patients not meeting colorectal cancer screening guidelines should undergo a flexible sigmoidoscopy, which has the advantages of less intensive preparation, less risk and discomfort, and no requirement for sedation.

Sigmoidoscopy (or colonoscopy) allows assessment for distal polyps or cancers that may cause constipation, distal proctitis (which can paradoxically present with constipation), solitary rectal ulcer syndrome or anal fissures, all of which can give symptoms similar to C-IBS.

Other than IBS, chronic constipation that is unresponsive or poorly responsive to laxatives can be due to slow colonic transit or an outlet (defecation) disorder; further workup may be beneficial, because these disorders may respond to other treatment modalities.

Slow colonic transit is most commonly caused by constipating medications (especially narcotics). Another entity, colonic inertia (or slow transit constipation), is on the severe end of the spectrum and is a neuromuscular disorder of the colon. Treatment for slow transit generally involves removing medications that may be contributing to constipation, followed by increasingly aggressive bowel regimens of laxatives (often in combinations) or enemas as required. Colectomy is very rarely required and should only be considered in the context of a comprehensive evaluation by a specialist, with clear objective evidence of poor colonic neuromuscular function.
Objective assessment of colonic transit is easily performed by a Sitzmarker test (Hinton test). Sitzmarks (Konsyl Pharmaceuticals, Inc, USA) are small radiopaque plastic markers that can be followed through the gastrointestinal tract once ingested. The patient takes a single Sitzmarks capsule (which contains 24 markers) with water (day 0). On day 5 , a single, flat-plate abdominal $\mathrm{x}$-ray is done. Retention of $20 \%$ or more of the markers at day 5 is abnormal. Retained markers throughout the colon or in the right colon are suggestive of slow transit, whereas grouping of the markers in the rectal area suggests an outlet disorder. The test is simple, safe and adequately reproducible for routine clinical use (14). It should be noted that this study may not be valid in a patient taking narcotics. Normal transit is consistent with a diagnosis of IBS, although IBS itself, as a motility disorder, can also cause slow transit. Defecation disorders may also cause 'outlet' constipation, and may be anatomical (eg, from a rectal prolapse or, more commonly, a rectocele) or functional. Symptoms often focus more on inability to get the stool out despite the urge. Excessive or prolonged straining, changes in positioning, or digitation around or in the anus to expel stool are symptoms suggestive of a defecation disorder.

Functional defecation disorders, also known as pelvic floor dyssynergia, pelvic floor dysfunction or anismus, are worth diagnosing because they may respond well to physiotherapy or biofeedback (15). When a subject attempts to defecate, there should be a rise in intrarectal pressure, which is coordinated with a decrease in anal sphincter pressure as the puborectalis and sphincter muscles relax. This manoeuvre is under voluntary control and is primarily a learned response. The inability to synchronize these motions is the main pathophysiological abnormality in patients with functional defecation disorders (16).

Evaluation of a defecation disorder can involve two tests: anorectal manometry and defecography (defecating proctography). Both of these tests may only be available in specialized centres. Anorectal manometry, as the name suggests, incorporates a manometric evaluation of the pressures of the anal canal during rest, squeeze and bearing down. Testing also typically includes assessments of rectal sensation using a balloon in the rectum. The rectoanal inhibitory reflex is also assessed. When a balloon is inflated in the rectum, a reflex relaxation of the internal anal sphincter should be observed. Because this reflex is mediated solely by the enteric nervous system, its presence confirms complete innervation of the colon and, thus, rules out Hirschsprung's disease. A final test consists of a balloon expulsion test, in which the patient attempts to expel the rectal balloon filled with a standardized volume of water into a commode. This provides an objective assessment of the patient's ability to defecate, because most healthy patients should be able to expel the balloon. Anorectal manometry and balloon expulsion are generally considered the gold standard tests for diagnosis of functional defecation disorders (14).

Defecography involves placing a barium paste into the rectum to simulate stool. The patient then attempts to defecate on a commode while undergoing fluoroscopy. Defecography provides useful information regarding the anatomical and, to a lesser degree, functional changes of the anorectum. It can show abnormalities that may not be clinically or endoscopically apparent, such as rectocele, mucosal intussusception, rectal prolapse or excessive perineal descent. Functional problems 
may be revealed as poor activation of the levator muscles, prolonged retention or the inability to expel the barium. Defecography alone, however, is not sufficient to make a diagnosis of pelvic floor dysfunction (17) but is particularly useful when a mechanical outlet problem is suspected.

It should be noted that results of transit testing and anorectal testing may overlap. Therefore, correlation of these results with the patient's symptoms is crucial. If anorectal testing is not available, it may be reasonable to proceed to physiotherapy (and biofeedback, if available) when symptoms and other testing suggest a functional defecation disorder. Pelvic floor physiotherapy, with a focus on education and re-coordination of the defecation manoeuvre, is available in most centres. There is no risk involved, and results are positive (16).

\section{OTHER TESTING}

Some recent literature has suggested that a proportion of patients with IBS (both C-IBS and D-IBS) may suffer from small intestinal bacterial overgrowth, and that hydrogen breath testing (with glucose or lactulose) may be a worthwhile diagnostic test to consider (18). However, these results have not yet been reproduced by other groups and, thus, should not be considered for routine use in the diagnosis of IBS.

Lactose intolerance has also been postulated as a common contributor to IBS symptoms (19). However, many people with documented lactose intolerance can tolerate small amounts of dairy products $(19,20)$, casting doubt on the validity of formal testing for this. In our opinion, a reasonable approach is to ask the patient to stop all dairy products for

\section{REFERENCES}

1. Mitchell CM, Drossman DA. Survey of the AGA membership relating to patients with functional gastrointestinal disorders. Gastroenterology 1987;92:1282-4.

2. Longstreth GF, Thompson WG, Chey WD, Houghton LA, Mearin F, Spiller RC. Functional bowel disorders. Gastroenterology 2006;130:1480-91. (Erratum in 2006;130:1480).

3. American Gastroenterology Association. American Gastroenterological Association medical position statement: Irritable bowel syndrome. Gastroenterology 2002;123:2105-7.

4. Spiller R, Aziz Q, Creed F, et al; Clinical Services Committee of The British Society of Gastroenterology. Guidelines on the irritable bowel syndrome: Mechanisms and practical management. Gut 2007;56:1770-98.

5. Cash BD, Chey WD. Irritable bowel syndrome - an evidence-based approach to diagnosis. Aliment Pharmacol Ther 2004;19:1235-45.

6. Saibeni S, Rondonotti E, Iozzelli A, et al. Imaging of the small bowel in Crohn's disease: A review of old and new techniques. World J Gastroenterol 2007;13:3279-87.

7. Abdo AA, Urbanski SJ, Beck PL. Lymphocytic and collagenous colitis: The emerging entity of microscopic colitis. An update on pathophysiology, diagnosis and management. Can J Gastroenterol 2003; 17:425-32.

8. Olesen M, Eriksson S, Bohr J, Jarnerot G, Tysk C. Microscopic colitis: A common diarrhoeal disease. An epidemiological study in Orebro, Sweden, 1993-1998. Gut 2004;53:346-50.

9. Fine KD, Seidel RH, Do K. The prevalence, anatomic distribution, and diagnosis of colonic causes of chronic diarrhea. Gastrointest Endosc 2000;51:318-26.

10. Tanaka M, Mazzoleni G, Riddell RH. Distribution of collagenous colitis: Utility of flexible sigmoidoscopy. Gut 1992;33:65-70.

11. Locke GR III, Pemberton JH, Phillips SF. AGA technical review on constipation. American Gastroenterological Association. Gastroenterology 2000;119:1766-78.

12. Rex DK, Bond JH, Winawer S, et al; US Multi-Society Task Force on Colorectal Cancer. Quality in the technical performance of colonoscopy and the continuous quality improvement process one to two weeks and to assess for any appreciable effect. If there is a clear reduction in symptoms (assuming no other dietary or lifestyle changes), then it may be reasonable to continue with the restricted diet, provided the patient maintains adequate calcium intake.

\section{DURABILITY OF DIAGNOSIS}

The diagnostic accuracy of IBS is excellent. Once the diagnosis of IBS has been made, long-term studies (21-23) have suggested that it does not change at re-evaluation in approximately $95 \%$ of patients. However, shifts in IBS symptomatology are common, with more than $75 \%$ of IBS patients switching between IBS subgroups (eg, M-IBS to C-IBS or D-IBS) over two years in one study (24). In that study, switches from D-IBS to C-IBS were less common (29\%) over the study period. However, where a clearly identifiable precipitant to the change can be identified (for example, medication use), reinvestigation is not necessary, assuming a continued lack of alarm features.

\section{CONCLUSIONS}

IBS is a very common entity, and typical symptoms without alarm features generally do not require exhaustive evaluation before initiating therapy. The disorder is chronic, and symptoms can be expected to wax and wane over time, often indefinitely. In patients with alarm features or diarrhea-predominant symptoms, or in patients who fail initial supportive management, further directed investigations are suggested. Differentiating functional defecation disorders from IBS may be worthwhile, because nonpharmacological therapies, such as biofeedback, have been shown to be useful in this population.

for colonoscopy: Recommendations of the US Multi-Society Task Force on Colorectal Cancer. Am J Gastroenterol 2002;97:1296-308.

13. Leddin D, Hunt R, Champion M, et al; Canadian Association of Gastroenterology, Canadian Digestive Health Foundation. Canadian Association of Gastroenterology and the Canadian Digestive Health Foundation: Guidelines on colon cancer screening. Can J Gastroenterol 2004;18:93-9.

14. Rao SS, Ozturk R, Laine L. Clinical utility of diagnostic tests for constipation in adults: A systematic review. Am J Gastroenterol 2005;100:1605-15.

15. Chiarioni G, Heymen S, Whitehead WE. Biofeedback therapy for dyssynergic defecation. World J Gastroenterol 2006;12:7069-74.

16. Rao SS. Dyssynergic defecation. Gastroenterol Clin North Am 2001;30:97-114.

17. Diamant NE, Kamm MA, Wald A, Whitehead WE. AGA technical review on anorectal testing techniques. Gastroenterology 1999;116:735-60.

18. Lin HC. Small intestinal bacterial overgrowth: A framework for understanding irritable bowel syndrome. JAMA 2004;292:852-8.

19. Suarez FL, Savaiano DA, Levitt MD. Review article: The treatment of lactose intolerance. Aliment Pharmacol Ther 1995;9:589-97.

20. Suarez FL, Savaiano DA, Levitt MD. A comparison of symptoms after the consumption of milk or lactose-hydrolyzed milk by people with self-reported severe lactose intolerance. $\mathrm{N}$ Engl J Med 1995;333:1-4.

21. Harvey RF, Mauad EC, Brown AM. Prognosis in the irritable bowel syndrome: A 5-year prospective study. Lancet 1987;1:963-5.

22. Owens DM, Nelson DK, Talley NJ. The irritable bowel syndrome: Long-term prognosis and the physician-patient interaction. Ann Intern Med 1995;122:107-12.

23. Svendsen JH, Munck LK, Andersen JR. Irritable bowel syndromeprognosis and diagnostic safety. A 5-year follow-up study. Scand J Gastroenterol 1985;20:415-8.

24. Drossman DA, Morris CB, Hu Y, et al. A prospective assessment of bowel habit in irritable bowel syndrome in women: Defining an alternator. Gastroenterology 2005;128:580-9. 


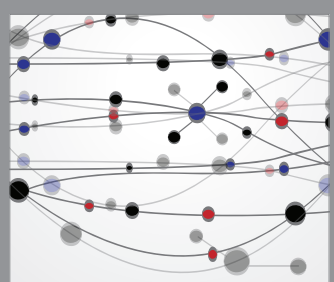

The Scientific World Journal
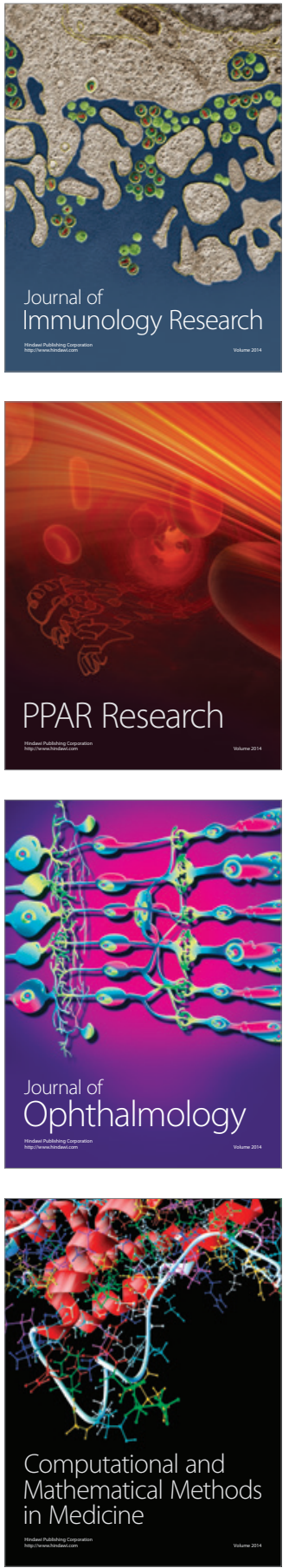

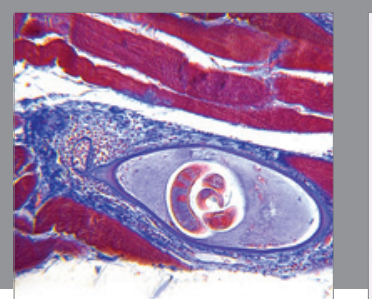

Gastroenterology Research and Practice

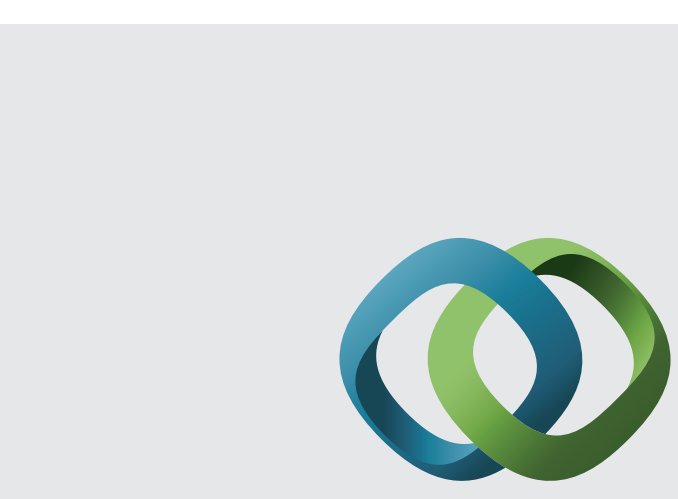

\section{Hindawi}

Submit your manuscripts at

http://www.hindawi.com
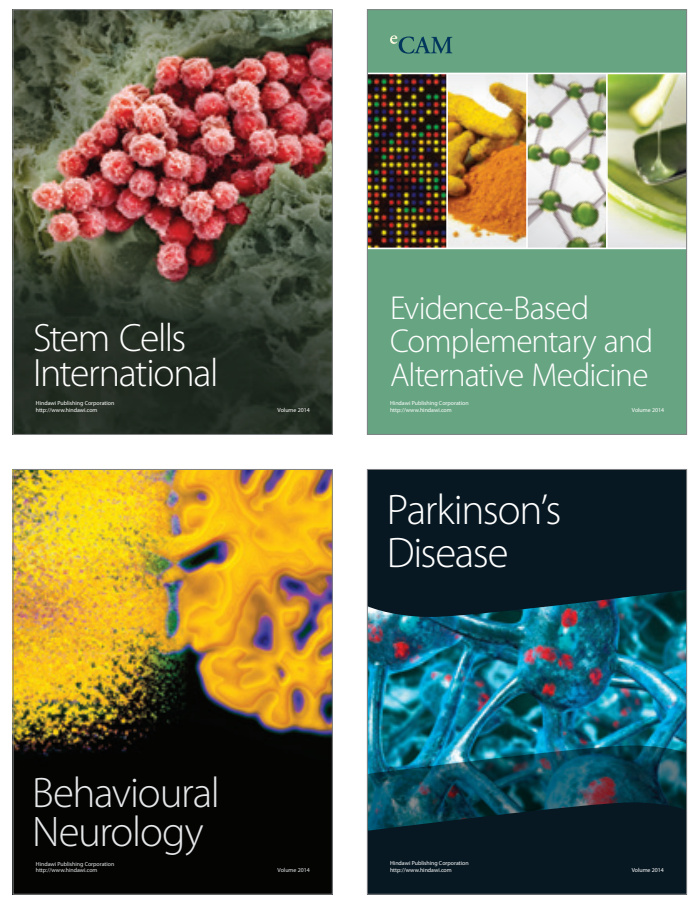
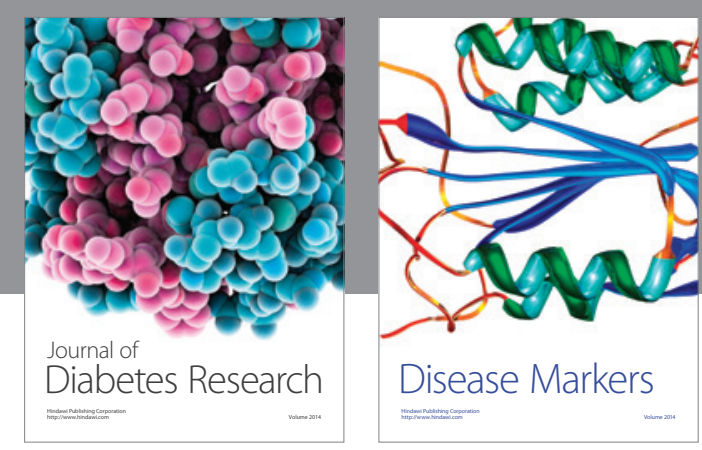

Disease Markers
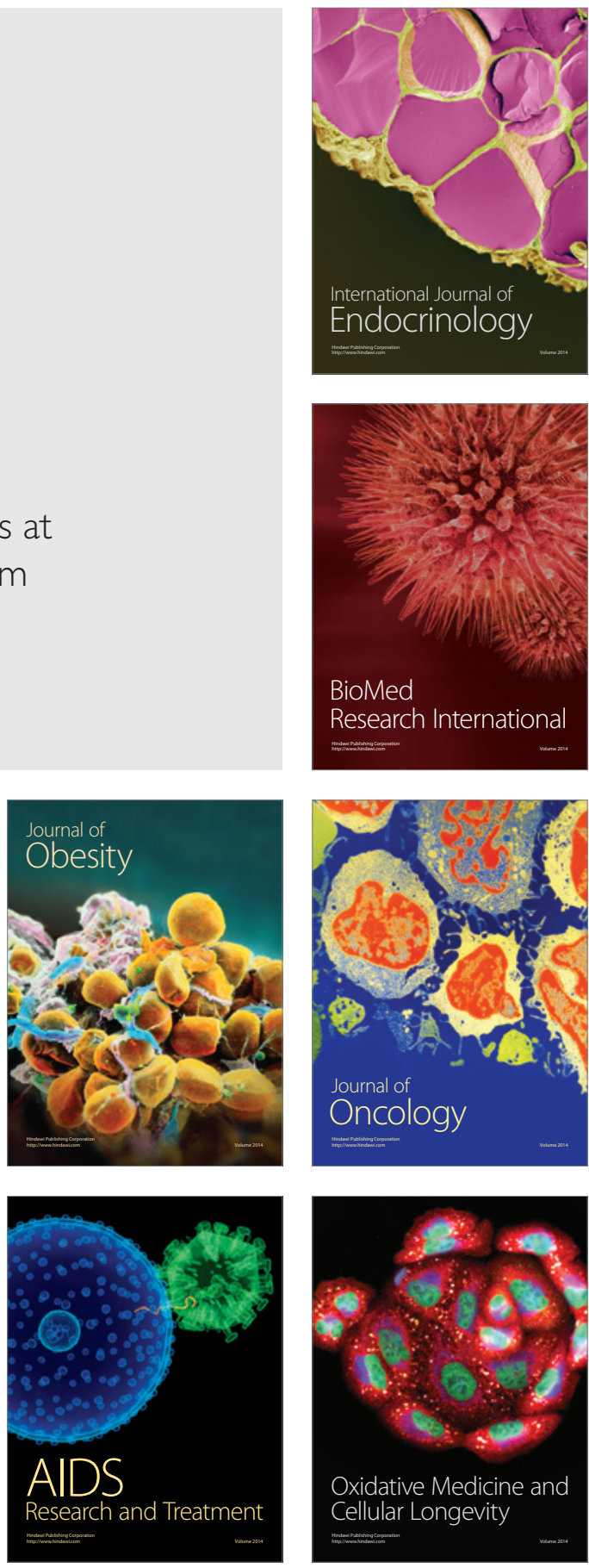